\title{
The Influence of Cultural Organization on the Application of Social Networks Based on New Technologies in Astara Customs Organization
}

\author{
Sanjar Salajeghe \\ Associate Professor and Department Director of management Ph.D., Islamic Azad University, Kerman \\ Email: Salajeghe_187@yahoo.com1 \\ Mohammad Reza Rezaeian
}

PhD student of Public Administration - Human Resource Management, Islamic Azad University, Kerman Email:mr.rezaiian@gmail.com

\section{Doi:10.5901/mjss.2016.v7n4s1p171}

\section{Abstract}

In the world of scientific communication, social networks can be considered as effective platforms in the production of science, sharing ideas, personal and social development. The goal of social network is to promote the level of science by providing communication possibility between individual capital and forming social capital. The general goal of every social network is to create social capital and facilitate communication between experts, artists and different professionals etc. Therefore, this research tries to consider "The influence of cultural organization on the application of social networks based on new technologies in Astara customs organization". Since we have detailed information about the number of experts in Astara customs organization, the statistical population considered limited that includes 138 persons, according to Morgan table; the statistical sample consists of 103 persons. In this research, both library and field methods are used for data collection. By using library method and studying books, articles, other researches and the existing information on the internet that are in the area of research interest, used for background and research literature and definition of indices. In this research, by using experts and professors' view, the factors associated with the subject are identified and preliminary questionnaire is provided using Likert rating scale. After determining its validation by identifying validity and for assessing reliability of questionnaire, Cronbach's Alpha for using Likert is used and final questionaries and required information are collected. Descriptive and inferential statistics used for analysis the data, descriptive statistics including the average frequency distribution table, standard deviation and etc. to answer to research questionaries' and conclusion of inferential statistics methods different tests by using SPSS22 and Smart PIC software: for normality of data, from the pearson correlation coefficient, MultiMate regression analysis, confirmatory factor analysis, to confirm the identification of questions and keywords of each component and structural equation modeling technique to study collected data mode Kolmogorov -Smirnoff test been used.

Keywords: organizational culture, Hafsted organizational culture model, social networks, new technologies, accepted model of divest technology.

\section{Introduction}

Social networks are new generation of internet web sites. In these websites, internets users gather around common axis virtually and create online communities (Molaie, 2010). Actually, social networks are networks that consist of peoples and groups and communication between them. Virtually social networks are a new generation of social relations space that although do not have much life; they could as well open in peoples life. Many peoples of different ages and from different social groups come together in the virtually social networks and from great distance in the real world communication together through social networks (Eslami 2012). Social networks have the dominant role in today's world and cannot ignore them. These sites effect on different dimensions of individual and social life and at the country level and even international, for this reason will pay more expanding far greater role in the future (Eslami 2012). In the world of scientific communication, social networking can be effective substrates in the production of knowledge, share ideas and personal and social developments. The aim of social networks is by providing ability to communication between the individual investors and social capital formation; help promote science (Rahmanzade, 2010). The overall goals of any social networks are creation social capital and facilitate communication between specialists, artists, and numerous professionals, and convert individual capital into social capital is important issue of all area of science. In this way, individual knowledge convert to collective knowledge and actually be exploited from collective wisdom for solve problems 
of world of science (Rahmanzade, 2010) Such a culture is introduced: integrated set of habits, included: thinking, to speak, to act and behavior, products based on human capacity for learning and use of knowledge for create social success (Adler, 1997).

Based on Hofstede, culture is mental suite that apart one member of the group from others.

4 dimensions of international culture according to Hafsted:

1. Avoid ambiguity: the extent to which the term of uncertain terms that are the member of culture, feel threatened.

2. Individualism: the extent to which the term of a culture, strengthens the position of individual.

3. Masculinity: the extent to which the terms of various genders describes the social and cultural.

4. Power distance: is the size in the terms of people with power plan and less decision in the country, accept unequal power distribution.

This research attempts to use Hofstede cultural model and also Davis technology acceptance model (TAM) and the Hybrid model under review "Effect of culture on use of social networks based on new technologies in Astara customs agencies" and respond to research questioners base on that "whether organizational culture base on the use of social networking technologies have impact on the organization or not".

\section{Research Literature}

\subsection{Foreign literature}

1. Lopes and Merono (2001) did research as "Effect of organizational culture on the use of ICT". Koen and Kamron used organizational culture model in research. The result of this research will show that ethnic culture and Adhocracy have direct effect on the use of ICT.

2. Teo , sin, Luan (2008) did research as " a cross- culture to use technology between MALAYSIA and SINGAPORE teachers to using technology acceptance model, and concluded that there are differences between the different sectors of culture in the two countries, but there is no difference in the ease of understanding and perceived usefulness.

3. Cordon and Marshal (2008) have been investigated research as "national culture and technology adoption" based on 95 national culture reviews and have concluded the high level of reliability and methods of avoiding doubt increases the management information systems and reduces average and lower than reception.

4. Soren and Kalayz (2004) in their study pay to compare the use of CIT staffs in the NORWAY in AMERICA.

5. Tan, Png, Wee (2001) did research as" the importance of national culture and it infrastructure acceptance "that this research conducted among 153 organizations in 24 countries. The result showed that dimensions of national culture are the important factors in the IT infrastructure.

6. Rking, Galletta, Maccoy (2007) accomplished study with title the acceptance application in the event of culture on 400 students from different universities of the world and concluded that generally anywhere from culturally different from elsewhere. Acceptance technology model maybe fall somewhere and not thrive elsewhere.

7. Hasan and Ditsa (1999) in their study reported about the relationship between MIS acceptance culture in two different regions in WEST AFRICA and the MIDDLE EAST that of all the IT factors must be considered, the most likely cultures are the most difficult factors to define and measure. Their findings were compared through eight cultural dimensions which includes four Hafsted social cultures.

8. Hong and Kim (2001) studied critical factors for MIS acceptance from an organizational perspective and concluded that organizational fit, organizational resistance and organizational culture play a key role in successful MIS acceptance.

\subsection{Maximum internal investigation}

1. Verms yare(2010) did research an entitled "effect of organizational culture on acceptance of management information system in government agencies Qazvin province ",have hierarchical that have inverse relationship with the adoption of management information systems, that means whatever the amount of the culture in the organization increase, the adoption of management information systems reduced.

2. Dargahi and Razavi (2004) did research an entitled "role of organizational culture in the implementation of telemedicine technology in the centers provide health services of Tehran university of medical science, this research has been done with the aim of study the role of organizational culture in use and the successful 
implementation of telemedicine technology in hospitals affiliated to Tehran university of medical science. As a result of the research, it would follow that culture and structure and organizational design affect in use and successful implementation of telemedicine technology in hospitals and other health and medical service provider country, results show that in terms of organizational culture this type of organizations ability to accept change have strategy and successful operation of telemedicine technology.

3. Sheikh shojaee and Olomi (2007) did research an entitled the factors affecting the acceptance of information technology by Liberians technical faculty of Tehran universities. This research has studied the factors affecting the acceptance of information technology by Liberians technical faculty of Tehran universities within the framework of manufacture agents' technology acceptance model.

The elements of this model are include perception of usefulness, perception of ease of use, and an attitude to use and decided to use IT.

Findings from this research showed factor producer "technology acceptance model" in this research have been identified factors affecting on acceptance of information technology.

4. Yazd khasti and Partners (2009) did research an entitled "relationship between organizational culture and the acceptance of total quality management in public universities in the country. The main aim of this research is check relationship between organizational culture and acceptance of total quality management in public universities in the country base on the opinion of faculty members.

5. Zahedi (2004) in article an entitled "relationship between organizational culture and organizational efficiency "did research in Asia insurance companies, Iran, Alborz and Dena in Tehran and to measure the efficiency (DEA) data envelopment analysis and complex analysis indicate that the difference in performance of insurance companies be explained only with one variables of the adaptability of organization culture, it means the paperwork.

6. Kordnaej and Moshabaki (2004) have tried an article on explaining the design and interaction model strategy, organizational culture environment in industrial organizations that review interaction model strategy, organizational culture and environment in industrial organization and base on research hypothesis tested the contact of them at 60 industrials and concluded that managers of design development and implementation appropriate strategy should pay attention to the type of environment play a fundamental role to participate in the process of creating and shaping the environment.

7. Rahimnia and Alizade(2009) in article an entitled "check dimensions of organizational culture base on Denison model" to pay the members of the board of Ferdowsi of Mashhad university to identify the size and characteristics affecting organizational culture compliance acceptance, engaging in work and consistency composed of mission. The results of research showed that from the perspective of the developers reply outlook greatly impact on organizational culture.

\subsection{Assumptions}

The main hypothesis:

Organizational culture has an effect on the use of social networks base on new technologies.

Hypothesis:

1. Avoid ambiguity, affect perceived usefulness by staff.

2. Avoid ambiguity; affect the perceived ease of use by staff.

3. Power distance, affects the perceived usefulness by staff

4. Power distance, affects the perceived ease of use by staff.

5. Masculinity/ feminism, affect the perceived usefulness by staff.

6. Masculinity/ feminism, affect perceived ease of use by staff.

7. Individual/ collectivism, affect the perceived usefulness by staff

8. Individualism/collectivism, affects the perceived ease of use by staff. 


\subsection{Conceptual research model}

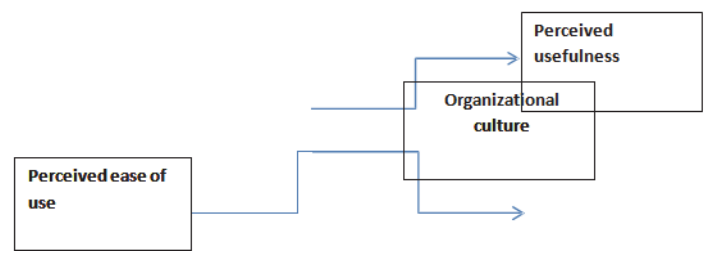

Therefore, the purpose of this research is to pay the use Hafsted organizational culture model(TAM) and the hybrid model review "effect of culture on the use of social networks based on new technology in Astara customs organization.

\section{Research Methodology}

The method based on two indicators, purpose of the research and data collection method arises, this research is an applied nature and objectives and the method of data collection is descriptive and correlational. Also the main strategy used in this research is cross-sectional survey in terms of non-experimental variable and in terms of time, according to given that research is done in a given time period specified.

\subsection{Subject domain, spatial domain, time domain}

Subject domain: this research is in the field of human resource management and management of organizational behavior and organizational culture.

Spatial domain: things research is Astara customs organization.

Time domain: the process of data collection that includes collection data and do more original quizzes and tests, distribution of the questionnaire interpretation of results starts from November2015 and ends March 2015.

\subsection{Tools and methods of data collection}

The data collection tools in the study are questionnaire. It should be mention that the individual and group interviewing was used in the completion of the process of gathering information. Rating scale was used for ranking the data in this questionnaire that wants respondents to express the rate of their agreement or disagreement with each item on the basis of an on 5-choice Likert spectrum.

\subsection{Papulation and sample size and sampling}

This research papulation included all employees of Astara customs organization are to include 138 people. Therefore, according to the limited papulation; the sample size applies Cochran formula which includes 103 people. It should be mention that sampling method in this research is simple random.

\subsection{The validity and reliability of questionnaire}

\subsubsection{Validity}

The validity that taken of word "valid", it means valid, and validity meaning is correct and true. The purpose of the validity is that measurement device is able to measure the features and characteristic. The importance of validity of the fact that inadequate and inappropriate measure could makes unnecessarily and unduly any practical research.

\subsubsection{KMO test}

There are various ways to measure validity that in this research according to the research variables consist of several dimensions, was used confirmatory factor analysis .In doing this analysis should ensure that can be used to analyze existing data or not. In the other words; whether the desired data suitable for factor analysis or not? For this purpose, 
$\mathrm{KMO}$ index and Bartlett's test were used. Because on these two tests when data are suitable for analysis that the KMO index more than (0.6) nearly one and Bartlett's test sig is (05.0). The output of these tests for each questionnaire are in the tables presented below:

Table 1: The questionnaire validity Variable

\begin{tabular}{|c|c|l|}
\hline Result & KMO & \multicolumn{1}{|c|}{ Variable } \\
\hline Confimed & $788 / 0$ & Organizational culture \\
\hline Confirmed & $776 / 0$ & Perceived usefulness \\
\hline Confirmed & $951 / 0$ & Perceived ease of use \\
\hline
\end{tabular}

\subsubsection{Reliability}

In this research, the questionnaire designed by the sample members, studied, completed and then with using the SPSS Cronbach's alpha variables was calculated. As shown in Table 2 since the Cronbach's alpha coefficient obtained for each variables and for questionnaire larger than 7.0. Therefore, we can say that the questionnaire has good reliability.

Table 2: The questionnaire reliability

\begin{tabular}{|c|c|c|c|}
\hline Result & Cronbach's alpha & The number of items & Variable \\
\hline Confimed & $76 / 0$ & 20 & Organizational culture \\
\hline Confimed & $79 / 0$ & 7 & Perceived usefulness \\
\hline Confimed & $81 / 0$ & 5 & Perceived ease of use \\
\hline Confimed & $84 / 0$ & 32 & $\begin{array}{c}\text { Total Cronbach's } \\
\text { alpha }\end{array}$ \\
\hline
\end{tabular}

\section{Data analysis}

In this research the descriptive and statistical inference techniques will be used within using descriptive statistics information about feature of demographic characteristics of respondents' offered. Then the distribution of research variables will be examined base on the central index(mean and median) dispersion indicators (variance and standard deviation) and indicators of distribution(coefficient of skewness and slenderness ratio).As well as SPSS software used to provide data and transfer it from Liserl software. In fact in the inferential with using confirmatory factor analysis the overall questionnaire structure of research is a bout validation, content. For confirmatory factor analysis and structural equation modeling standard operating time is calculated. The power relationship between the operation (hidden variable) and visible variable is shown by the load factor.

\subsection{Descriptive statistic}

\subsubsection{Features of demographic sample}

\subsubsection{Gender}

In this section the demographic characteristics of the sample are described. 
Table 2: The frequency distribution of respondents in term of gender

\begin{tabular}{|cccc}
\hline Variables studied & Gender & $\begin{array}{c}\text { Number of } \\
\text { repetition } \\
\text { percent }\end{array}$ & frequency \\
\hline Group gender & Female & 30 & $28 \%$ \\
& Male & 73 & $72 \%$ \\
\cline { 2 - 4 } & Total & 103 & $100 \%$
\end{tabular}

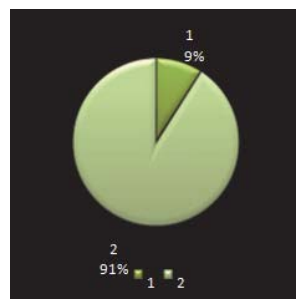

Figure 1: Condition of the respondents in terms of gender

Table 3: The frequency distribution of respondents by age

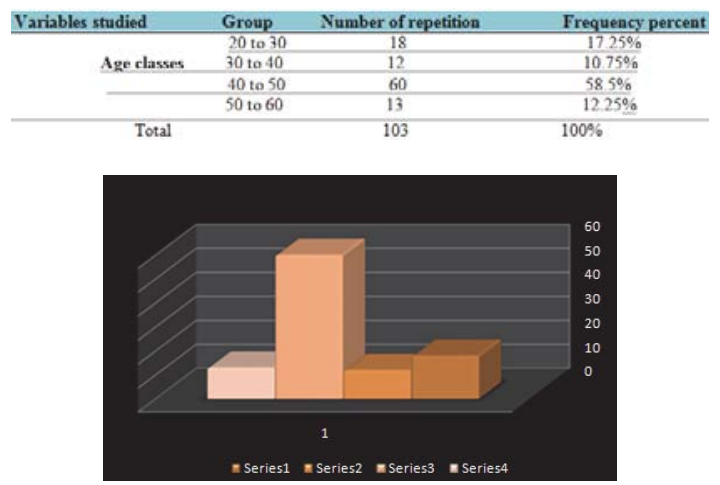

Figure 2: Status of respondents in terms of age

Table 4: The frequency distribution of respondents in the term of educational level

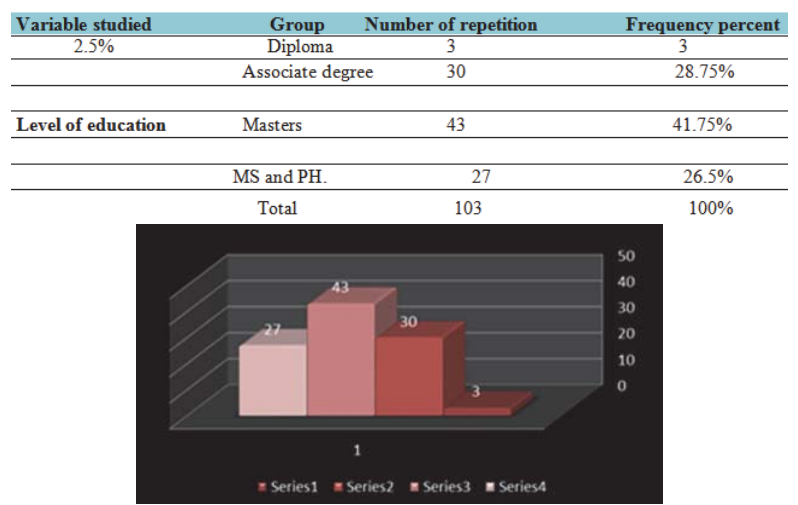

Figure 3: Status of respondents in the term of educational level 


\subsection{Inferential statistics}

\subsubsection{Normality and variables}

The test applied to get a license to the use of regression and Pearson correlation coefficients on the dependent and independent variables to be shown normality of the information in test based on the assumption below to check the normality of the data has been input:

The data that are normally distributed: $\mathrm{HO}$

The data that are not normally distributed: $\mathrm{H} 1$

According to the Komogrov-smirnov test table, if significance level for all dependent and independent variables larger than test level $(0.05)$ data distribution is normal.

Table 6: Test result of Komogrov-smirnov research variables

\begin{tabular}{lcccccc} 
Variable & Number & Mean & Standard deviation & Z circumstantial evidence & Significancelevd \\
\hline Avoid ambiguity & 103 & 3.51 & 0.735 & 1.036 & 0.234 \\
Power distance & 103 & 3.72 & 0.558 & 1.054 & 0.190 \\
Masculinity feminism & 103 & 3.55 & 0.771 & 1.155 & 0.139 \\
lndividualism collectivism 103 & 3.00 & 0.680 & 1.194 & 0.115 \\
Perceived usefulness & 103 & 3.0 & 0.848 & & 1.338 \\
\hline
\end{tabular}

As is clear from data Table (6), the significance level for all research variables is larger than 0.05 .As a result of all the variables in this research has the same distribution.

Table 7: Compact dimension research variables table

\begin{tabular}{|c|c|c|}
\hline Variable & variable & symbol \\
\hline Avoid ambiguity & AVA Individualism/collectivism & LAP \\
\hline Power distance & perceived usefulness & PEU \\
\hline Masculinity/feminism & perceived ease of use & EAU \\
\hline
\end{tabular}

\subsubsection{Confirmatory factor analysis of the questionnaire}

The final model is clearly seen that the relationship between all variables that said in primarily model of research is positive and significant. The strength of the relationship between factors (latent variables) and visible variables is shown by the load factor. Load factor is a value between zero and one. If the load factor is less than one is considered poor relation and will be ignored. Load factor between 0.3 to 0.6 is acceptable and if it is larger than 0.6 is very good (Beshlideh, 1392).When the correlated between variables was identified, must be done meaningful test.

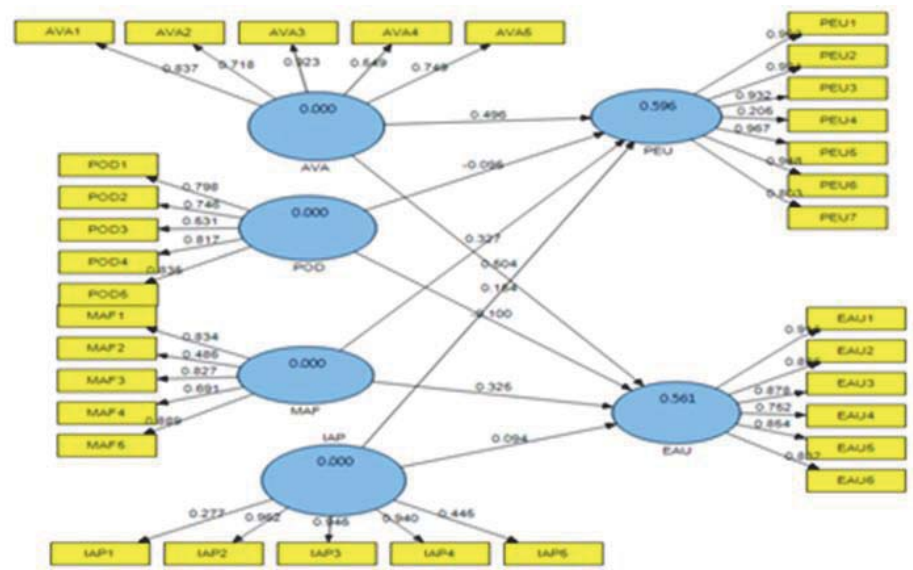

Figure 2: Standardized coefficients conceptual model 


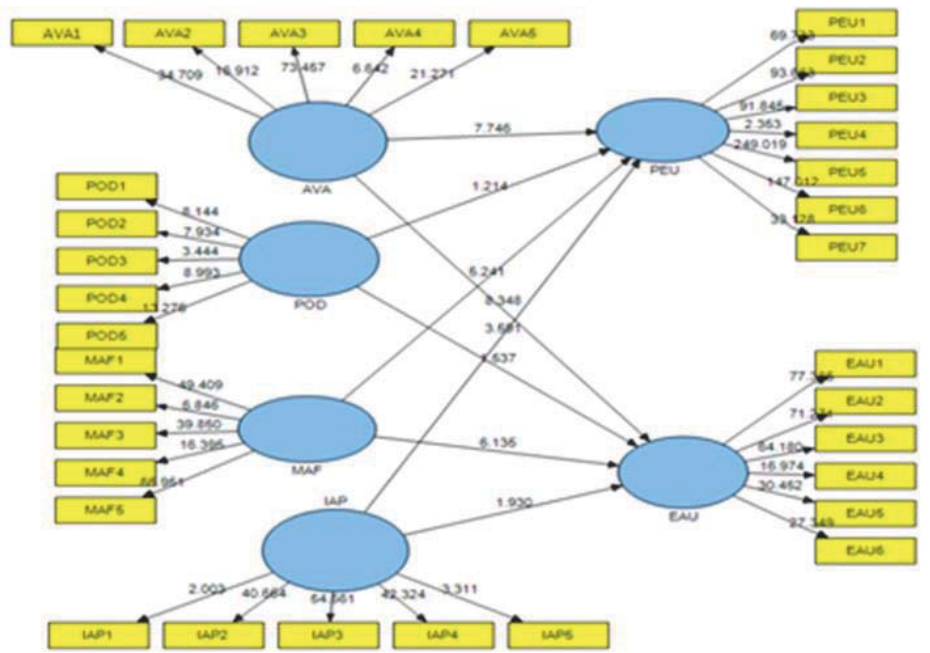

Figure 3: Students t-test result for meaningful path

\subsubsection{Goodness of fit}

Finally for basic hypotheses structural model used the number of indicators of goodness of fit. The below table represent the fitting indicators. The below table show that the conceptual research model for explain and fit is in good condition.

Table 8: Indicators structural model

\begin{tabular}{|l|l|l|}
\hline Result & Required amount & Fit index \\
\hline 2.472 & $<3.00$ & $\mathrm{X}^{2} \mathrm{DF}$ \\
\hline 0.95 & $>0.90$ & GFI \\
\hline 0.057 & $<0.08$ & RMSEA \\
\hline 0.034 & $<0.05$ & RMR \\
\hline 0.90 & $>0.90$ & NFI \\
\hline 0.97 & $>0.90$ & IFI \\
\hline 0.92 & $>0.90$ & CFI \\
\hline
\end{tabular}

For meaningful test; the path coefficients between variables will use of software out.

\subsubsection{Research hypothesis}

To examine the hypothesis and significance path coefficient test, between variables used software output. Path and the significant result are given in the below table

Table 9: Result of evaluation of the structural model

\begin{tabular}{|c|c|c|c|c|}
\hline \multicolumn{2}{|c|}{ Path } & \multirow{2}{*}{$\begin{array}{l}\text { Path } \\
\text { coefficient(B) }\end{array}$} & \multirow{2}{*}{$\begin{array}{l}\text { A significant } \\
\text { number(t- } \\
\text { value) }\end{array}$} & \multirow{2}{*}{$\begin{array}{l}\text { The } \\
\text { coefficient of } \\
\text { determination } \\
\mathrm{R}^{2}\end{array}$} \\
\hline From variable & To variable & & & \\
\hline $\begin{array}{l}\text { Avoid ambiguity } \\
\text { Power distance } \\
\text { Masculinity/ } \\
\text { feminism } \\
\text { Individualism/ } \\
\text { collectivism }\end{array}$ & $\begin{array}{l}\text { Perceived } \\
\text { usefulness }\end{array}$ & $\begin{array}{l}496.0 \\
095.0 \\
327.0 \\
154.0\end{array}$ & $\begin{array}{l}746.7 \\
214.1 \\
241.5 \\
581.3\end{array}$ & 5960 \\
\hline $\begin{array}{l}\text { Avoid ambiguity } \\
\text { Power distance } \\
\text { Masculinity' } \\
\text { feminism } \\
\text { Individualism/ } \\
\text { collectivism }\end{array}$ & $\begin{array}{l}\text { Perceived ease of } \\
\text { use }\end{array}$ & $\begin{array}{l}504.0 \\
1.0 \\
325.0 \\
094.0\end{array}$ & $\begin{array}{l}348.8 \\
537.1 \\
135.6 \\
930.1\end{array}$ & 561.0 \\
\hline
\end{tabular}


As clear from figure 2and 3 and table 8 , index-linked, cross-validation redundancy for all latent variables, is positive. Therefor the structural model of appropriate quality; It means the independent variables to predict the dependent variable. According to software output and review the adequate of the index conceptual model it follows that, the model present in this study, is a good model.

It also in this research perceived usefulness structures has R2, the amount of 596.0 that assessed in the average and to construct perceived ease of use this equates to 561.0 , which is average and as a result, the relationship between these three structures in the conceptual model assess the median communication that suggests the strength of the research conceptual model.

The main hypothesis of research: organizational culture affects the use of social networks based on new technologies.

To examine the main hypothesis and effect of organizational culture on the use of social network bivariate regression was used separately. The result of this test are given in the below table.

Table 10: Result of bivariate regression analysis on the use of social networks

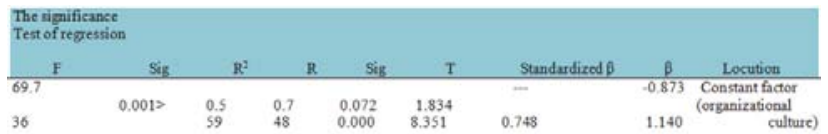

According to the amount of $\mathrm{F}$ and relevant $\mathrm{p}$-value, the result that regression is significant .Also the coefficient of determination is obtained 559.0 indicate that 9.55 percent of changes related to the use of social network, it is explain by organizational culture.

\section{Result and Recommendation}

Table 11: Hypothetical results

\begin{tabular}{|l|l|l|}
\hline $\begin{array}{l}\text { Confirm or reject } \\
\text { hypothesis }\end{array}$ & \multicolumn{1}{|c|}{ Hypothesis } & $\begin{array}{l}\text { Number of } \\
\text { hypotheses }\end{array}$ \\
\hline Confirmed & $\begin{array}{l}\text { Organizational culture affect the use of social networks based on } \\
\text { new technology }\end{array}$ & 1 \\
\hline Confirmed & Avoid ambiguity affect perceived usefulness by staff & 2 \\
\hline confirmed & Avoid ambiguity perceived ease of use by staff & 3 \\
\hline rejected & Power distance affect perceived usefulness by staff & 4 \\
\hline rejected & Power distance affect perceived ease of use by staff & 5 \\
\hline confirmed & Masculinity/ feminism affect perceived usefulness by staff & 6 \\
\hline confirmed & Masculinity/ feminism perceived ease of use by staff & 7 \\
\hline confimed & Collectivism/individualism affect perceived usefulness by staff & 8 \\
\hline confirmed & Collectivism/individualism affect perceived ease of use by staff & 9 \\
\hline
\end{tabular}

\subsection{Managerial and practical notes and recommendation}

In connection with the result, according to priory, the effect of secondary variables on the dependent variable according to the coefficient obtained the following recommendations are offered to users:

It should be noted that the directors recommended due to the effect of the hypotheses in research to allocate resources and spend money and time in their organization.

1. Avoid ambiguity effect of perceived ease of use by staff.

According to the staff (Astara customs organization) in the administrative system of Iran, according to Hafsted studies that constitute part of the society avoid ambiguity levels are low, therefor it is recommended that managers and assistants to reduce the level of ambiguous space in conjunction with ease of use of social networks in order to raise awareness of Astara customs organization pay to effective training courses and also with the assistance and development of human resource strategies that cause kept better the organization customs and strength sense of stability and security that somehow opposite side of the concept avoid ambiguity.

2. Avoid ambiguity affects the usefulness perceived by staff.

According to the fact that the tolerance of ambiguity of staff in relation to the employees perception of the 
usefulness of the use of social networks affects recommended. When the organizations experts (statistical society) especially in the category of middle age, due to lack of knowledge and awareness of the function of social networks, ability to resist the use of day communication technologies with few documented to conclude that, using these networks are effective in accelerating and facilitating of their work. Organizations managers to reduce the work ambiguous space, pay the briefing course in order to consider the beneficial role of importance and use of social networks.

3. Masculinity / feminism affect the perceived of usefulness by staff.

According to the effect of masculinity and feminism on perceived of usefulness by staff it is suggested that managers first, according to atmosphere of his/ her organization both male-oriented ( such as bravery, courage, competitive, materialism) or female- oriented (or pay to women's values and attitudes such as education and quality of life and their relationship) and according to the result of the aforementioned factors, is to be paid buildings positive view on staff in order to work with relevant social networks.

4. Effect of masculinity and feminism on perceived ease of use by staff in Astara customs organization.

As the factors associated with masculinity and feminism, the perceived ease of use is an effective by staff, it is suggested that managers hold short-term training course in order to create desire in their work with social networks until they fully understand their ease of use of social networking.

5. Effect of individualism /collectivism on perceived usefulness by staff in Astara customs organization Due to the effect of individualism and collectivism on the perceived usefulness of social networking is recommended, managers on individualism and collectivism factors indicates the extent to which people in a community prefer their relative to others and remain independent from the emotional and feeling of groups , organizations and other form of group, according to the strategies and annual communicated policies of officials senior that pay attention to consider on employees perceptions of the usefulness of effective social networking.

6. Effect of individualism and collectivism on perceived ease of use by staff in Astara customs organization

Despite the low effect of index and collectivism on the ease of use of staff from social networks. In Astara customs organization, can be offered to managers, apply for example in the prevailing atmosphere of pluralism in the organization using the working group and teamwork's and bottom- up planning and participatory decision making and ....that strengthens to create space for pluralism in the organization.

7. Effect of power distance on perceived ease of use by staff in Astara customs organization.

According to reject the hypothesis, it is recommended to managers and deputy, because dose not adversely affect, power distance on perceived ease of use and using material and non-material resource of organization and time spent on energy and manpower costs avoid which will wasting it.

8. Effect of power distance on perceived ease of use by staff in Astara customs organization

According to reject the hypothesis, it is recommended to managers and deputy, because does not adversely affect, power distance on perceived usefulness and using material and non- material resource of organization and time spent on energy and man power and costs avoid which will wasting it.

\subsection{Suggestion for future research}

1. Be paid to the effect of culture on the day and very common complication subject web surfing (use misplaced) in the working environment of the internet and social networks.

2. Be paid to review and rooting, causes of confirm or reject hypothesis at the end of thesis. For this, the emphasis is recommended in addition to gathering tool. Used individual or group interviews.

3. In addition to Hafsted, done to investigate the effect of other proposed models in culture including Denison organizational culture model, Estefan robin's, Kola khan and Bakfern and Ganter Jeffry sanctified Lion and Este ringer Harrison model on social networks in Astara customs organizations.

4. It is suggested that this research run in service area such as banking industry and production and industrial companies and compared their results.

5. It is suggested for future research, review and be studied the role and effect of descriptive statistics including gender age and education on the results obtained from the responses to the questionnaires.

\subsection{Limitations of the study}

Limitations that this research has faced include the following: 
1. Lack of information and adequate internal records related to the subject

2. This research was conducted as title (questionnaire) that is the cause of deprivation of liberty respondents to answer questions, which may not be consistent with result.

3. Impossibility of using different questionnaire due to time constraints registration, other limitations of the research, because the comprehensive performance evaluation process and the full assessment different aspects of culture a different ways of being employed in this research can contain more precise results.

\section{References}

Stephen Robbins (management of organizational behavior), third volume, translated by Ali Persian and Seyed Mohammad Arabi, first edition, Tehran institute of research and business studies1995, pages 972-974.

Ali Atafar (organizational culture and how to create its evolution0, Isfahan seminar work of culture, 1996, pages 4, 5

Stanley Davies (management culture makers), translated by Naser mirsepasy and Parichehr motamed gorji, second edition, Tehran, Morvarid publication1997.

Asghar zomorodian (change management, strategies and application of new patterns), first edition, Tehran, publication industrial management institute, 1994, page 82

Delavar, Ali (2001), research methods in psychology and educational science, Tehran: Virayesh publication.

Sardari, Ahmad (2004), examine the relationship between organizational culture on job satisfaction in research centers dependent on the ministry of science, research and technology in Tehran.

Sarmad, Z; Bazargan Abas; Hejazi Elahe (2004), research methods in the behavioral sciences, Tehran, Agah publication.

Esmito Antoni (1989), geopolitical information, translated by Fereidun shirvani, Tehran: Islamic republic of Iran publication.

Ahmadnia, Shirin, the effect of sociological social networks in family,

Ehzazi, Sh (1997), sociology of the family: with emphasis on the role, structure and functional family in modern times, publication of intellectuals and women's studies, college textbook in Iran.

Akbaritabar, Hezarjaribi A (2011), a study on the effect of social networks on the lifestyle and leisure youth, (pages 11-17).

Akbaritabar A (2012), study of social networks: case study of networks and u24, master's thesis in sociology at the Tarbiat Modares University under the guidance of Doctor Ali, saie.

Mir Mohammad sadeghi, A, 1982, virtual social network analysis with Tehran nodal: Qian computer

Naghib Sadat, seyed Reza, family management in dealing with social networks.

Namakdost, Hasan (1391), join social media from Gutenberg to internet

Alvani, seyed Mehdi (1386), public management, Tehran, 2007, thirtieth edition, page 157.

Webster, Frank (2004), theories of the information, translated by Esmaeel Ghadimi, second edition, Agah publication.

Hosseini F, correlation of Rafie, Salahshorian A, and Heidari perceived social support and size of social network with quality of life dimension in cancer participents, Kams journal (FEYZ). Research 2008; 12(20) in Persian

Kawachi I, social ties Fitzmaurice G RAMM EB ENGPM1 and change in social ties in relation to subsequent total and cause- specific mortality and coronary heart disease incidence in men. American journal of Epidemiology 2002; 155(8):700-9 (1998) "social capital: its origin and applications imports modern society". Annual review of sociology 24:1-24

Ghasemi A, prediction of quality soltani $\mathrm{E}$ shareh $\mathrm{H}$ life of non-insulin- dependent Diabetic patients based on perceived social support. Zahedan J Res Med Sic (ZJRMS).2012; 14(2): 82-5 in Persian

Valente TW, social network influences on adolescent substance use: An introduction .Connection 2003; 25(2):11-6 